\title{
New Methods of Research in Aeronautics
}

THE twentieth Wilbur Wright memorial lecture, 1 delivered before the Royal Aeronautical Society by $\mathrm{Mr}$. H. E. Wimperis, on May 26 , under the above title, is of twofold interest to scientific readers. It gives an account of the work now in progress in aeronautical research. It also includes a more abstract discussion upon the aims of aeronautical research in Great Britain, the difficulties that confront it-not the least of which are those of finance-and the methods by which it is hoped they will be overcome.

Mr. Wimperis began by commending the methods of the Wright brothers as being the soundest in scientific research. They "made thousands of tests ... and tabulated thousands of readings". Few persons actually engaged in research will quarrel with that commendation. The paper then describes the organisation of aeronautical research in Britain, and pays tribute equally to the progress made by the scientific workers and to the aircraft industry's ability in utilising information so obtained. Mr. Wimperis scarcely gives full credit to Britain for its relative contribution to the world's aeronautical knowledge ; in fact, he more than once apologises for the inadequacy of the equipment, both in use and proposed. It is hoped to be able to use this limited amount of apparatus for the unhindered solution of various problems, by skilful adaptation, and extending results so obtained upon a basis of mathematical and physical reasoning.

The new British compressed air tunnel will be able to obtain a Reynolds number 1.93 times that of the only other one in existence in the U.S.A., by working at an air pressure of 25 atmospheres. The solution of many of the problems met in the course of the development of this apparatus has been very materially helped by the full and free communication of all available information from the National Advisory Committee for Aeronautics in America. Incidentally, the policy of delaying the building of this tunnel until the U.S.A. Committee had fully explored theirs has been fully justified, and the truly international aspect of scientific research, when unhampered by political affairs, is emphasised.

The large wind channel to be erected at the Royal Aircraft Establishment at Farnborough is to be only $24 \mathrm{ft}$. diameter, against the $60 \mathrm{ft} . \times 30 \mathrm{ft}$. cross seetion of a similar one in America, and will use 2000 h.p. for air propulsion, as compared with $6500 \mathrm{~h}$.p. in the large American tunnel. It will thus be cheaper both in first cost and running expenses. A 24-ft. tunnel can be used to investigate all problems that must inevitably be so done, that is, those incapable of being attacked by direct full scale experiments during flight. These are all connected with the central part of an aeroplane, principally the cooling of engines, resistance of the body and its parasitic parts, and the investigation of airscrews. Problems upon the behaviour of the actual wing structure can be, and have been, successfully measured in full scale flight on a special Parnall research monoplane, and such results can be added to those found in the tunnel for the more complex parts around the body.

A vertical wind tunnel for the investigation of spinning is also described. The air in this moves upwards, so that the spinning model, while falling relative to the air, is actually kept in the plane of observation and measurement by the operator. These experiments raise extremely complex problems upon the validity of transferring results from models of one size to another, or comparing results at different speeds, because of differences in mass, moments of inertia about various axes, etc. The effect of the sudden movement of control surfaces is reproduced by a delay action mechanism incorporated in the model.

The visual examination of air flow has obvious uses in aeronautical research. This is accomplished by the introduction of smoke from titanium tetrachloride for slower speeds. For higher speeds, shadowgraphs are taken from air heated by passing it across an electrically heated wire and viewing the model in its wake, either stroboscopically or photographically. When conditions are analogous, water can be used, and the motion examined either by watching illuminated oil bubbles or by focusing a microscope upon 'objects' in the water.

Experiments upon the suppression of noise are of interest not only for themselves, but also for the necessary development of the technique of the measurement of noise in 'decibels'. Considerable progress has been made in the insulating of the interior of an aircraft cabin from noise, but not so much upon the suppression of the noises at the source.

An ambitious programme of work on flying boat hulls and floats is outlined for the new tank at the R.A.E., Farnborough. Although the size of the tank is being limited, it is hoped to investigate all that is necessary by examining the behaviour of the model during the inevitable acceleration and deceleration in each run. It so happens that these are the two periods of greatest interest to designers, as the only parts of a seaplane's normal travelling life on the water are spent in either of these operations. Here again there will be considerable mathematical difficulties concerned with problems of mass, açceleration, and dynamical similarity.

The address concludes with a tribute to all those who have been concerned with the work of producing and handling machines for the Schneider contest. Mr. Wimperis expresses his satisfaction that these competitions have now automatically ceased, as the risk to the flying personnel was out of all proportion to the value of any results likely to be obtained from the mere further increase of flying speed alone. Nevertheless, the value of the technical progress that has been made in this respect is not to be underestimated.

\section{Early Maya Culture in Northern Yucatan*}

COBÁ, if only on account of its size, is one of the most important centres of culture in the Maya area of Central America. If, and when, its ruins are excavated, it is not improbable that it may prove crucial in the solution of a number of obscure

* A Preliminary Study of the Ruins of Cobá, Quintana Roo, Mexico. By J. Eric Thompson, Harry E. D. Pollock, and Jean Charlot. (Publication 424.) Pp. vii $+213+18$ plates. (Washington, D.C.: Carnegie Institution, 1932.)

$$
\text { No. } 3270 \text {, VoL. 130] }
$$

problems connected with early Maya colonisation in northern Yucatan. Since its ruins were discovered in 1926 by Dr. T. W. Gann-it was not then known that it had been visited by Teobert Maler in 1891 five further expeditions of the Carnegie Institu ion have been engaged in exploration and survey work on the site.

Cobá, which is situated in the Mexican province of Quintana Roo in the north of the Yucatan Peninsula, 